\title{
Example of Academia / Industry Professional Organization Engagement in STEM Outreach Activities
}

Dr. Timothy J. Jacobs, Texas A\&M University

Associate Professor in Department of Mechanical Engineering at Texas A\&M University

Dr. Charles E. Baukal Jr. P.E., John Zink Co. LLC

Charles E. Baukal, Jr. has a Ph.D. in Mechanical Engineering, an Ed.D., and Professional Engineering License. He is the Director of the John Zink Institute which offers continuing professional development for engineers and technicians. He has nearly 35 years of industrial experience and 30 years of teaching experience as an adjunct. He is the author/editor of 13 books on industrial combustion and is an inventor on 11 U.S. patents. 


\title{
Example of Academia / Industry Professional Organization Engagement in STEM Outreach Activities
}

\begin{abstract}
:
The growing interest in supporting STEM disciplines creates an opportunity for professional organizations that include members from academia and industry to participate in the recruitment and engagement of K-12 students. Professional organizations, because of their industry partners and members, are often in unique situations to center on specific focus areas and are composed of individuals interested in service and outreach. Further, professional organizations are routinely managing present-day "issues" facing certain industries and / or focus areas, creating opportunities for disseminating "real-time" relevance to prospective young students. This paper highlights the efforts of one such professional organization - the Central States Section of the Combustion Institute (CSS/CI) - in creating and executing an Outreach Program that solicits and funds proposals from high school teachers who use the funds to augment their science / engineering classes with some exposure to combustion. The program, now in its fourth year with four successful competition windows, has created opportunities for members of academia and industry to become exposed to issues that K-12 educators face in terms of engaging students in STEM disciplines. The objective of this paper is to provide a guide for professional organizations that consist of members of academia and industry to use in creating their own outreach program and to identify opportunities for bridging the gap between professional organizations and K-12 students and educators. The paper describes the process for developing the CSS/CI program, summarizes "lessons-learned" and provides what are believed to be essential features for making a K-12 outreach program successful.
\end{abstract}

\section{Introduction}

Professional organizations and societies continue to serve important roles in engineering, including for example: supporting professional development courses [1], motivating the everchanging purpose of an engineer [2], offering professional certification [3, 4], providing opportunities to enhance leadership skills, particularly among women, of early career faculty (and presumably industry engineers) [5], developing important industry-oriented course content alongside faculty [6], establishing an identity for professionals in a given field [7], continuing to promote the accessibility of engineering profession to women [8], and improving students' collegiate experiences [9]. Some organizations are actively involved in publishing papers and journals (i.e., knowledge dissemination), developing and enforcing codes and standards (i.e., public safety and engineering integrity), and providing outreach to encourage pre-college students to consider STEM disciplines. This article focuses on the latter feature, in which the Central States Section (CSS) of the Combustion Institute (CI) - a professional organization centered on combustion scientists and researchers - has executed a STEM outreach program to high school teachers.

The CSS / CI, founded in 1966, provides close and frequent contact among Combustion Institute members residing in the geographic area of the Central United States (i.e., Alabama, Arkansas, 
Illinois, Indiana, Iowa, Kansas, Kentucky, Louisiana, Michigan, Minnesota, Mississippi, Missouri, Nebraska, North Dakota, Ohio, Oklahoma, South Dakota, Tennessee, Texas, and Wisconsin), promotes science and application of combustion, and provides a single forum whereby the diverse scientific and engineering disciplines can be brought together to interchange information related to combustion science and applications. The Combustion Institute is an educational non-profit, international, scientific society whose purpose is to provide and disseminate research in combustion science. There are 34 sections of the Combustion Institute (one of which is the Central States Section). The main activity of the Combustion Institute is the International Symposium on Combustion. The symposia attract members of the Combustion Institute as well as others interested in combustion from around the world. The synergism produced at these symposia makes them the principal forum for presenting and integrating combustion research results. Members of both the CSS and the CI come from varied organizations representing industry, academia, and national laboratories / research centers.

Since the CSS is a non-profit organization, its Advisory Panel actively seeks opportunities to reinvest funds toward organization and membership development and growth. An effort was started in 2010 to actively use available funds to invest in outreach programs that enhance the science, technology, engineering, and mathematics (STEM) disciplines. Through a process, described in this paper, a teacher grant program was established to enable teachers the opportunity to enhance their science and engineering-oriented classrooms with combustion science learning modules. The program made its first official award in Academic Year (AY) 2011 - 12, and has successfully executed annually since then.

The objective of this paper is to describe the CSS Teacher Grant program and, in doing so, highlight the benefits and opportunities that academia / industry professional organizers receive by engaging in STEM outreach activities. The paper follows an unconventional format for a typical research-oriented conference paper; it is meant to be descriptive rather than resultsoriented (although qualitative results are suggested). Following this Introduction is a description of the process followed to execute the program. The program itself is then described. Finally, the program highlights the projects that have thus been funded through the grant program. The article concludes with a summary of the key benefits and challenges of an academic / industry partnerships in operating a grant program.

\section{Description of Process}

The idea to develop an outreach effort within the CSS started several years before the program began to materialize. Casual discussions of implementing an outreach program were generally met with positive agreement, but serious discussions never succeeded without a specific person being tasked with executing the ideas. Professional organizations that comprise academia, industry, and national laboratory researchers, scientists, and engineers are generally volunteerbased. Thus, any new initiative or effort of a program requires a champion or team of dedicated volunteers to materialize the ideas. Thus, the second major step of the process, following the initial kernel of the idea, was to create a dedicated officer position who would be responsible for leading the effort to create the new program. In addition to finding a lead organizer, a group of dedicated volunteers should be identified and committed to giving direction and feedback about 
the program. Finally, the organization should be willing to commit the necessary financial resources to make the program attractive for participants in the program.

It is important to clearly identify the objective when establishing a new program. Since the CSS was interested in some type of outreach activity, there were several ideas discussed. These ideas included:

1. New faculty support programs

2. Undergraduate student or graduate student scholarship / fellowships

3. High school student scholarships

4. High school teacher grants

It is difficult to assess the merits of the above-listed ideas without first establishing the objective of the outreach program. In other words, all ideas are good ideas without a clear objective. Thus, the committee established an objective of the program, which helped to guide the development process even further.

Once the objective of the program was defined, the CSS proceeded to develop the details of the program (e.g., timeline, award amounts, application requirements, review procedures, recognition efforts, and grantee reporting expectations). The details were assembled in a proposal that was reviewed and vetted by the committee, ultimately receiving approval from the CSS Advisory Panel.

Upon approval by the chief agency, the lead champion is responsible for executing the program and engaging the support committee at appropriate times to distribute the work load and ensure there is ownership among the members of the group.

Finally, after the program is executed, it is necessary to evaluate the program and assess its ability to meet the professional organizations' overarching goal. If appropriate, and resources continue to exist, iterations can be implemented to improve the program. In summary, the steps taken to execute the outreach program within an academic / industry professional organization is as follows:

1. Kernel the idea

2. Assign a dedicated champion

3. Form a support committee

4. Commit resources (including financial)

5. Define objective

6. Assemble, present, and approve program

7. Execute program

8. Evaluate program and iterate

\section{Features of the CSS/CI Teacher Grant Program}

The CSS's Teacher Grant program is targeted for high school teachers to develop and introduce a combustion science-based (i.e., applied chemistry) learning module into their course curriculum. Combustion science deals with fast exothermic oxidizing reactions that occur in the majority of energy, industrial, transportation, and fire suppression-based applications. 
Combustion science is a broad field consisting basically of chemistry, thermodynamics, heat transfer, and fluid mechanics. There are four major objectives with this program:

1. to expose high school students to the present and future challenges of combustion science research and development of technology,

2. to augment high school teachers' current and on-going efforts to enhance STEM-based curricula,

3. to coordinate a mentor / mentee relationship between combustion researcher and teacher, and

4. to invest in the education of potential future combustion scientists and engineers.

The cycle for the program begins in spring of the previous academic year, when the professional organization provides initial approval to proceed with the program and initially commit funds to potential awardees. For example, for the AY11-12 program, approval was granted to the Outreach Chair at the April 2011 Advisory Board to proceed with the AY11-12 program. Since the grant program centers on engaging high school teachers, a call for proposals is issued before the end of school of the previous academic year (e.g., AY10-11), with proposals due near the end of September of the new academic year (e.g., AY11-12). This is meant to give teachers enough time to become familiar with the program, and possibly identify combustion science mentors to help with writing the proposal and executing the grant should they receive an award. During the proposal writing stage, applicants are encouraged to request to be paired with a combustion researcher mentor to assist with providing technical information about combustion.

The program awards up to $\$ 5000$, and provides additional funds to cover travel expenses for the awardees to attend the CSS technical conferences for two years (typically less than \$1500 per teacher per year for travel expenses, which are covered by the CSS/CI). Awardees attending their first conference are expected to describe their proposed learning modules, interact with other attendees at the conference, and receive assistance with and feedback on the development of their combustion science materials. Awardees attending their second conference are expected to describe the learning modules that were actually developed and implemented, any measures of impact that modules had on their students, and any efforts to disseminate the learning modules to other teachers for broader use.

The proposal itself is restricted to five type-written pages (with additional details on formatting and font-size) and is expected to describe the following elements (which also serve as the merit review criteria):

1.the general topic of combustion science (i.e., applied chemistry) around which the learning module will be structured (e.g., stoichiometry of oxygenated fuels, calculated and measured flame temperatures as function of stoichiometry and / or fuel, and types of combustiongenerated pollutants and techniques for pollutant mitigation),

2.the general structure / pedagogy employed in the learning module,

3.the basic activities the learning modules will require students to conduct,

4.the expected improvement to the curriculum for enabling students to meet state / national proficiency requirements,

5.the expected use of award funds (including cost estimates),

6.a timeline of implementation, 
7.an approach to broadly disseminate and demonstrate ease of adoption of developed course materials to other teachers (e.g., hosting a workshop or presentation at a National Science Teachers Association meeting or creation of YouTube videos) and

8.confirmation that attendance to the first and second years CSS technical conferences are compulsory (all expenses paid by CSS / CI).

Further, applicants are requested to include a letter from the school principal that acknowledges: 1) the proposed effort will be supported and implemented to the maximum allowed capabilities of the school's resources, 2) awarded monies are made to the school on a reimbursable basis, for up to two-years after the date of the award notification and that the monies must be spent as proposed by the teacher, and 3) teacher attendance at the first and second years CSS technical conference will be allowed.

Once the proposal due date passes, the chair of the program assembles the proposals and distributes them to the review committee, which in the case of the CSS is the same members as the Outreach Committee. The chair of the committee remains neutral during the review process in order to provide fair consultation to applicants and ensure the sanctity of the review process. The committee members are asked to review the proposals based on the above-listed eight merit review criteria. Typically, the committee members have about 4 weeks to complete the review. Upon submission of the reviews, the chair evaluates the reviews and develops a ranking of the proposals. The ranking, which lists the proposals in order of likelihood of funding based on reviewers' scores, is sent to the committee members for final discussion and approval. The committee-reviewed and -approved ranking is sent to the CSS Advisory Board for final approval and commitment of award monies.

After approval of the awardees by the CSS Advisory Board, the chair of the Outreach Committee notifies the potential awardees in early to mid-December with a non-committing initial notice of award. This initial notice typically requests the potential awardee to provide additional information as requested by the CSS Advisory Board, provide a statement of commitment to safety as combustion experiments can be dangerous, and provide a release of liability to the CSS should any unfortunate accident happen as a result of activities developed with the grant funds. Potential awardees are asked to return this information by mid-January.

Upon receipt of the additional information requested from the teachers, a final award notice is issued, a press release generated, and an announcement posted on the CSS / CI website. The awardees are asked to attend the next CSS technical conference which usually takes place sometime between March and May. They then implement their proposed learning modules during the following academic year and attend that year's technical conference to report out their developed materials and dissemination materials. Finally, the awardees are asked to generate a short report that describes the learning modules which is posted on the CSS/CI website; this usually takes place the following summer.

From start to finish, the program takes about $2-2.5$ years for a given teacher's grantee period. 


\section{Challenges and Key Features of Success}

In general, the CSS Teacher Grant program is successful in attaining its objectives. Of particular note is the program's ability to grant awards for four consecutive years and successfully complete the full cycle of two teacher grant programs.

In spite of these successes, there are two key elements that serve as both a challenge and a necessary element of success. The challenge is recruiting teachers to provide a proposal. In academia and industry, it is regular business to write proposals and budgets for research and / or development projects. Very few high school teachers, however, have this experience. Thus, it does not come natural or obvious about how to write and submit a proposal. Consequently, the number of submitted proposals to the CSS Teacher Grant program has generally been low.

With this challenge has been made obvious a very important feature of success: the mentor. Every submitted proposal has had a mentor who worked with the high school teacher, encouraging submission of proposal, helping write a technically sound proposal, and ensuring the teacher is well-supported in developing the learning materials. Further, the mentor can be a familiar face at the required conferences, enabling the teachers to overcome any fears or doubts they may have about mingling with an academic / industry organization. Without a mentor, high school teachers may feel intimidated and otherwise unenthused to take on additional effort to promote the program's core objectives.

One of the key elements that an academic / industry collaborative organization can provide is the necessary and ever-helpful mentorship to properly engage students at an early level, including engagement with their teachers.

\section{Description of Example Projects}

As described above, two teachers have fully completed the cycle of the grant program. Summaries of their projects are included to help explain the purpose and objectives of the program.

\section{AY11-12: Mr. Tim McLinden, Catholic Central High School (Springfield, Ohio)}

In January 2012, Mr. Tim McLinden of Catholic Central High School (Springfield, Ohio) received a grant after competitive review process from the Central States Section of the Combustion Institute. Mr. McLinden proposed to center efforts on increasing the exposure of combustion to first-year chemistry students. As a result of his efforts and collaboration with Dr. Vince Belovich (US Air Force Research Laboratory, Dayton, Ohio), the following activities were completed as part of the grant:

- Heavier emphasis placed on combustion throughout the whole year. This was beneficial since it made the experiential laboratories (described below) and guest instruction (Dr. Belovich, described below) more meaningful.

- Experiential laboratory on the operation of a Bunsen burner. This was beneficial since it enabled students to understand the concept of combustion as a reaction involving a 
hydrocarbon fuel and oxygen, with a proper ratio of the two necessary for clean combustion.

- Experiential laboratory on liquid ethanol combustion. This was beneficial since it enabled to students to visualize the physical processes involved in combustion (e.g., liquid vaporization, premix zone, and flame lift off).

- Experiential laboratory on magnesium metal combustion. This was beneficial since students were able to see a metal-based combustion (i.e., rapid and exothermic) process as opposed to a slow oxidation process (e.g., iron rusting).

- Increased practice with balancing equations. This was beneficial since students were able to see combustion as a balanced chemical reaction and have discussions about fuel-lean, fuel-rich, and stoichiometric mixture ratios.

- Experiential laboratory on measuring $\mathrm{CO}_{2}$ and $\mathrm{O}_{2}$ products from ethanol / air combustion. This was beneficial since students were able to verify their theoretical calculations from balanced combustion reaction to measurements.

- Guest classroom instruction by area combustion researcher (Dr. Vince Belovich). This was beneficial since the students learned from Dr. Belovich several practical and theoretical aspects of combustion (e.g., parts of a jet engine, laminar vs. turbulent flames, and pre-mixed vs. diffusion combustion), observed demonstrations (e.g., burning of ethanol vs. jet fuel), learned what it's like to have a career / profession in combustion (specifically) and STEM (generally), learned about the importance of combustion, and learned about the future needs of combustion development.

The following were identified strengths of the program:

- Early exposure to combustion concepts helped students gain more from the laboratories and guest instruction.

- Teacher attendance and participation at the Combustion Institute meetings helped provide material for instructional instruments and laboratories.

- Students enjoyed using the high-tech equipment purchased with the grant money.

- Guest instruction by Dr. Belovich was an excellent capstone to the year's emphasis on combustion.

The following are lessons-learned:

- Some experiments planned will require more time to design and engineer for in-class use.

Mr. McLinden intends to continue the combustion-based instruction in his chemistry classes for the foreseeable future and hopes to make videos of the classroom demonstrations for YouTube posts and other media dissemination channels.

AY12-13: Ms. Melissa McCarthy \& John Weitlauf (West Lafayette, Indiana)

In January 2013, Ms. Melissa McCarthy of William Henry Harrison High School (West Lafayette, Indiana) and John Weitlauf of Benton Central High School (Oxford, Indiana) received a grant after competitive review process from the Central States Section of the Combustion Institute. Ms. McCarthy and Mr. Weitlauf proposed to center efforts on increasing the exposure of combustion to second-year Chemistry students and Engineering Design \& Development students. As a result of their efforts and collaboration with Dr. Steven Son 
(Professor of Mechanical Engineering, Maurice J. Zucrow Laboratories, Purdue University, West Lafayette, Indiana), the following activities were completed as part of the grant:

- October

o David Reece (Aeronautics and Astronautics Doctoral Student, Maurice J. Zucrow Laboratories, Purdue University) presented information based on Amateur Propellant Theory and Processing

- November

o Engineering Design \& Development students researched rocket designs.

o Chemistry students started small scale tests of reactants to determine the best proportions of the HTPB and AP with the help of Dr. Victor Barlow, a board member of the Indiana Rocketry Club.

o Engineering Design \& Development students continued to research rocket designs and then began the design phase of model rocket fuselage.

- December

o Chemistry students continued small scale tests of reactants to determine the best proportions of the HTPB and AP.

o Engineering Design \& Development students continued to design model rocket fuselage.

- January

o Chemistry students created cylinders of propellant, manipulating ammonium perchlorate crystal size, aluminum particle size and type and video recorded flame size and duration of flame.

o Engineering Design \& Development students continued to design model rocket fuselage.

o Engineering Design \& Development students began to build model rocket fuselage prototypes and test the prototypes for flight stability.

- February

o McCarthy presented preliminary findings of research as a workshop at the Hoosier Association of Science Teachers in Indianapolis, Indiana February 7, 2013.

o Engineering Design \& Development students continued to build model rocket fuselage prototypes and test the prototypes for flight stability.

- March

o Chemistry students produced rocket motors at Maurice J. Zucrow

Laboratories, Purdue University.

o Engineering Design \& Development students continued to build model rocket fuselage prototypes and test the prototypes for flight stability.

- April

o All students met at Thunderstruck 5 (Indiana Rocketry's major launch event) and launched the rockets, with the help of Dr. Victor Barlow! This was an amazing experience for students and teachers, alike!

- May

o McCarthy presented grant proposal and findings at the 2013 8th Joint US National Combustion Meeting in Park City, Utah on May 22nd, 2013. 
Ms. McCarthy and Mr. Weitlauf intend to continue the combustion-based collaboration in their Chemistry and Engineering Design \& Development classes for the foreseeable future and hope to continue making videos of the design processes. They plan to include the launch as a culmination of the research and design process. Launching at Thunderstruck events will also serve as a celebration of collaborative efforts between students in two different school districts.

\section{Conclusions}

This article presents an overview of an outreach program that issued from a professional organization that consists of members of academia, industry, and national laboratory / research centers. The program offers grant funds to high school teachers to develop specific STEMoriented learning modules, with the intention to raise aware of specific technical fields and generally interest and engage students in STEM careers. The article describes the process followed to develop the program, the program and its timeline, the key challenges and factors of success, and example projects resulting from the award program.

The key conclusion of the article is that the chief element of success of the program is the use of mentors to help guide the proposers and awardees of the grant program. These mentors are members of the professional organization, thus they participate in an academia / industry cooperation. Bridging academia and industry is critically important for the future of STEM education and advancement, and the described program is one simple microsm of how such interactions work favorably. On-going work will attempt to study the effectiveness of the program using surveys of student and teacher participants.

\section{Acknowledgements}

The authors wish to thank the Central States Section of the Combustion Institute for supporting the Teacher Grant program. Additionally, the authors wish to thank the members of the CSS Outreach Committee who are not also co-authors, including Dr. Indrek Wichman (Michigan State University), Dr. Stephen Ciatti (Argonne National Laboratory), and Dr. Michal Benjamin (General Electric). Finally, the authors acknowledge the high school teachers featured in this article (Mr. Tim McLinden, Ms. Melissa McCarthy, and Mr. John Weitlauf), the teachers continuing to work through their grant programs (Mr. Andy Schaafs and Mr. Jason Roberts), and their respective mentors (Dr. Vince Belovich, Dr. Steve Son, Dr. John Graf, and Dr. Marc Baumgardner); their motivation, leadership, and dedication to STEM education have made this program successful.

\section{References}

1. Brizendine, A.L., Continuing professonional development of engineering, engineering technology, and industry personnel. 1988 ASEE Annual Conference, 1998.

2. Cuello, J.L., Designing a Global Ethic for Engineers. 2003 ASEE Annual Conference, 2003.

3. Walter, S. and D. Walden, Associate systems engineering professional (ASEP) certification: A credential tailored for sstudents and junior engineers. 2010 ASEE Annual Conference, 2010. 
4. Alungbe, G., et al., Professional certification in construction in USA. 2008 ASEE Annual Conference, 2008.

5. $\quad$ Bush, T. and L.J. Genik, The importance of the disciplinary society in leadership skill development and advancement. 2013 ASEE Annual Conference, 2013.

6. Hole, L.D., D.W. Radebaugh, and K.A. Soschinske, Strategies for industry and university cooperation in engineering ethics education. 2005 ASEE Annual Conference, 2005.

7. Brown, P.S. and P.A. Seaburg, The Architectural Engineering Institute -- A professional society for architectural engineers. 1999 ASEE Annual Conference, 1999.

8. Aultman-Hall, L. and B. Holmen, Promoting women as leaders for engineering: The role of individuals, organizations and professional societies. 2006 ASEE Annual Conference, 2006.

9. Durham, S.A. and W.E. Marshall, Enhancing a student's engineering experience through participation on student organizations. 2012 ASEE Annual Conference, 2012. 